\title{
The Strategies in Global Semiconductor Industry: The SWOT Analysis of Samsung Electronics Company
}

\author{
Duygu Hidiroglu \\ University of Mersin
}

This paper provides useful insights about the external and internal analyzes of Samsung Electronics Company and the situational analysis of Semiconductor Industry. Internal analysis of Samsung Electronics Company has been conducted according the company's firm culture and value, weaknesses, strengths, core competencies and business level strategies. Based on the situational dynamics (strengths, weaknesses, opportunities and threats) of Samsung Electronics Company designs its environment. In short, the main objective of this study is making deep research on Semiconductor and other technology integrated industries while deeply analyzing the external and internal dimensions of sector leaders both in global and in leader countries such as U.S.A., Korea and China.

Keywords: SWOT analysis, Samsung Company, semiconductor industry, external analysis, business level strategies

\section{INTRODUCTION}

After its establishment in China in 1938, Samsung Electronics Company made a leap forward especially after the 1950s; has become competing with the leaders of the semiconductor industry. Today, Samsung Electronics Company has become one of the largest electronic device manufacturers in the world. Samsung Electronics Company is a South Korean technology company. Producing all kinds of electronic products from dishwashers to smart phones, Samsung has been one of the strongest and most prominent names in the field of technology in the last one and a half years (Shin, 2017).

Samsung Electronics Company specializes in the production of a wide variety of consumer and industrial electronics, including mobile devices, televisions, digital media devices, semiconductors, memory chips and integrated systems. It has become one of the best-known names in technology and produces around one-fifth of South Korea's total exports (Brown and Linden, 2011). So much so that many people now call Samsung with companies called technology giants; Apple started to be mentioned along with Facebook, Microsoft, Amazon and Google.

This study aims to reach critical analysis results about the external and internal forces influencing the Samsung Electronics Company and the Semiconductor Industry. These analyzes are done in respect to the strategies both in industrial level and Samsung Electronics Company's operational and business level. Samsung Electronics Company designs its environment by regulating realistic strategic plan and applying right strategic management practices. This is critical process for Samsung Electronics Company since it has to benefit from its own strengths while eliminating its weaknesses. Further, Samsung Electronics Company should also take advantages of the opportunities and protect itself from threats in its environment. 
On the basis of product quality, price and advanced technology; Samsung Electronics Company proves to be superior to other rivals that producing technological products (PC's, flash memories, chips, DRAMs, mobile phones, LCDs etc.) for its industry. The study has reached inner insights and useful conclusions for the future researches and practical implementations and suggestions especially for Samsung Electronics Company and any other companies which aim to be accomplished in these industries.

\section{LITERATURE}

\section{The History of Samsung Electronics Company}

Samsung Electronics Company was established in 1969 to manufacture black and white TV sets. In 1992, Samsung Electronics Company developed the World's first 64MB DRAM. In 1994, Samsung Electronics Company developed the World's first 128MB DRAM. In 1996, Samsung Electronics Company had begun the mass production of 64MB DRAM. In 2000, Samsung Electronics Company developed the World's first 512MB DRAM. In 2001, Samsung Electronics Company had begun the mass production of $512 \mathrm{Mb}$ Flash Memory Device (Non-Volatile) (Kang, 2010). In 2003, Samsung Brand Value had ranked 25 th in the World by Interbrand.

\section{The Overview of Samsung Electronics Company}

Samsung Electronics Company has five business divisions. These are:

- Semiconductor; Memory \& Logic Chips: Memory Chip Market (DRAM, Main Memory Produced, Utilized in Other Facets of Electronics) and Flash Memory (Currently 32\% of Memory Chip Market, Rapid Growth Market),

- Digital Media; TVs \& Computers,

- LCD; LCD Panels for notebook computers, monitors \& HDTVs,

- Telecommunications; Mobile Phones \& Network Equipment,

- Digital Appliances; Refrigerators \& ACs (Lee and Kim, 2011).

\section{FIGURE 1 \\ PETA BYTES OF DEMAND IN SAMSUNG ELECTRONICS COMPANY (2017-2020)}

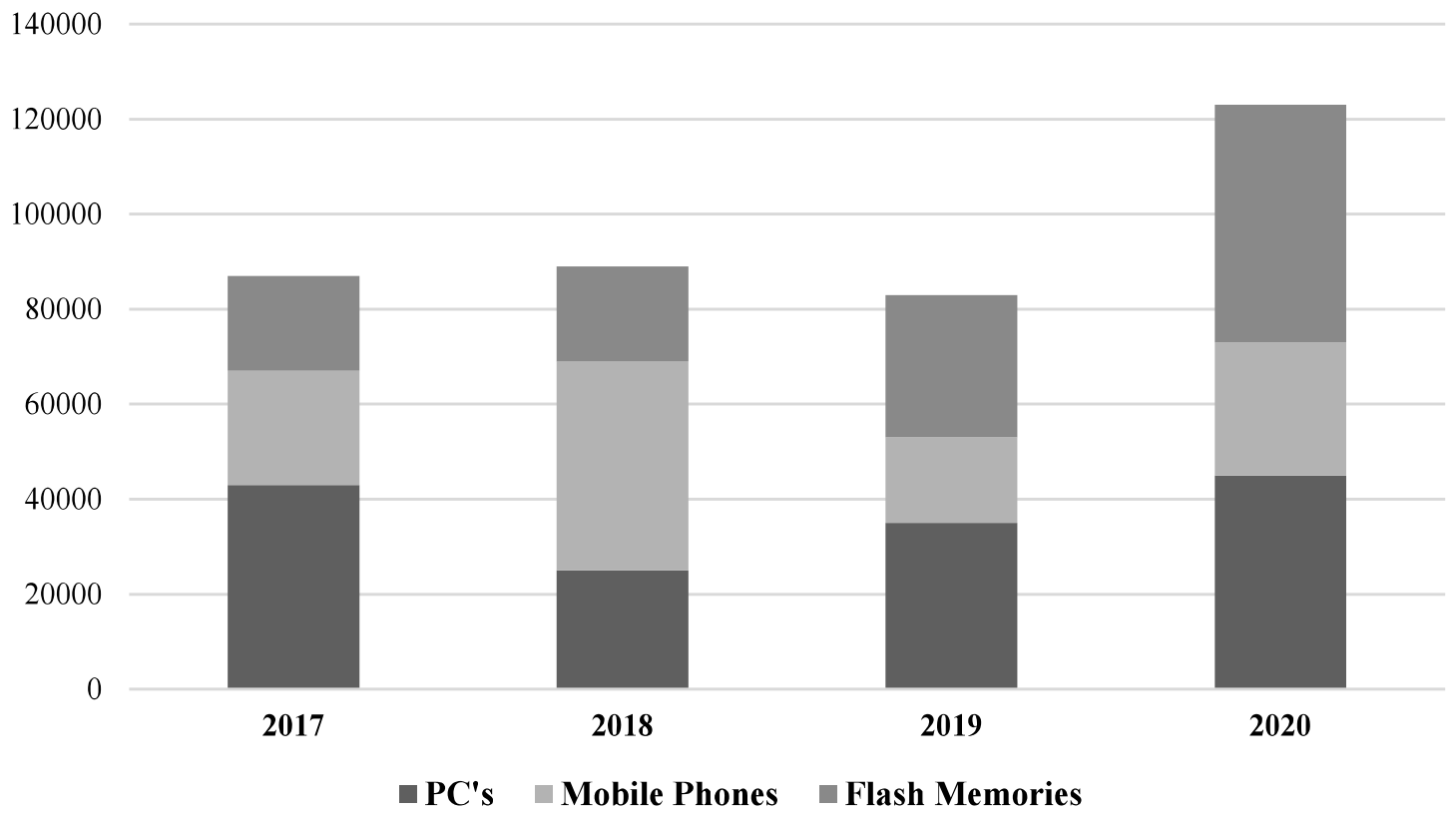

Source: https://eu.community.samsung.com/ 
Samsung Electronics Company is the world leader in advanced memory technology currently. The company has announced its strategies to develop its production capacity of NAND flash in Pyeongtaek, Korea. This strategic decision is because there has arisen the necessity of reinforcing Samsung Electronics Company's ability to meet demands in emerging technology markets. The company has already started construction of production area in order to begin the mass production of Samsung's cutting-edge V-NAND memory before the end of the year 2021.

Korea will be second largest market of Samsung Electronics Company since Korea is still a developing country, there so many untouched markets in terms of high-tech technology.

In the past, Samsung Electronics Company's brand value increased about $\$ 7.4$ billion in 4 years, placing it at $21^{\text {st }}$ in the world in terms of brand value (Liao and Chen, 2020). Samsung Electronics Company has sustained continuous growth on the regards of its brand value. The company was ranked in 43rd place in the Interbrand's list of global brand value in 2000. The total net sales of Samsung Electronics Company were reached \$135 billion in 2004 as well. Samsung became the largest company in South Korea in 2005. Samsung Electronics Company had 337 overseas operations in 58 countries and employs 212,000 people worldwide at that time (Kang, 2010). In 2012, Samsung Electronics Company had ranked in number 9 at the list of global brands and continued to grow and reached 6th place in 2017 at that global brand value list.

Samsung's move upwards in Interbrand's list of 100 most valuable brands in the world was backed by the continuous introduction of innovative products and implementation of broad marketing activities on the global stage. Today, Samsung Electronics Company has ranked in 5th place with its brand value of $\$ 62.3$ billion. Additionally, Samsung Electronics Company has announced that it has counted in number 5 in the Best Global Brands 2020 list published by Interbrand. Although there is a huge uncertainty and many negative conditions due to COVID-19 pandemic, Samsung Electronics Company has observed 2\% rise in its brand value. The company's brand value was $\$ 61.1$ billion in 2019 and now it has been $\$ 62.3$ billion in 2020 (Daft, 2020).

\section{THE CONCEPTUAL FRAMEWORK}

The main issues about Samsung Electronics Company being required to be discussed in this study are stated below. This study aims to discuss and analyze the external and internal issues of Samsung Electronics Company and to suggest some solutions in order to provide the sustainability of Samsung Electronics Company's success in that competitive environment. The issues that Samsung Electronics Company has dealt with in recent period are mentioned in below brief discussions.

- How should Samsung Electronics Company cope with the new Chinese threats?

- Today growing Chinese competition threatens each market actor due to its low price, and ease of obtaining capital (Sodhi and Lee, 2007).

- What product markets should Samsung Electronics Company focus on?

- Samsung Electronics Company has 5 divisions, and it is important to maintain focus in one of these divisions.

- How should Samsung Electronics Company change or modify its dual level strategy in order to become stronger?

- Samsung Electronics Company's dual level advantage is low production costs and premium product prices for a high-quality product (Lewis, 2002). It is vital for Samsung Electronics Company to improve or modify this advantage to be successful in the market.

- Which new strategies does Samsung Electronics Company require?

In order to meet the main goals of this study, the external and internal analysis will be completed by following parts. In addition, the study will focus on the four issues stated above to make proper and practical suggestions to Samsung Electronics Company on the purpose of the company's success. 


\title{
THE STRATEGIES IN GLOBAL SEMICONDUCTOR INDUSTRY: THE SWOT ANALYSIS OF SAMSUNG ELECTRONICS COMPANY
}

\author{
External Analysis of Samsung Electronics Company
}

\author{
FIGURE 2 \\ EXTERNAL ANALYSIS OF SAMSUNG ELECTRONICS COMPANY
}

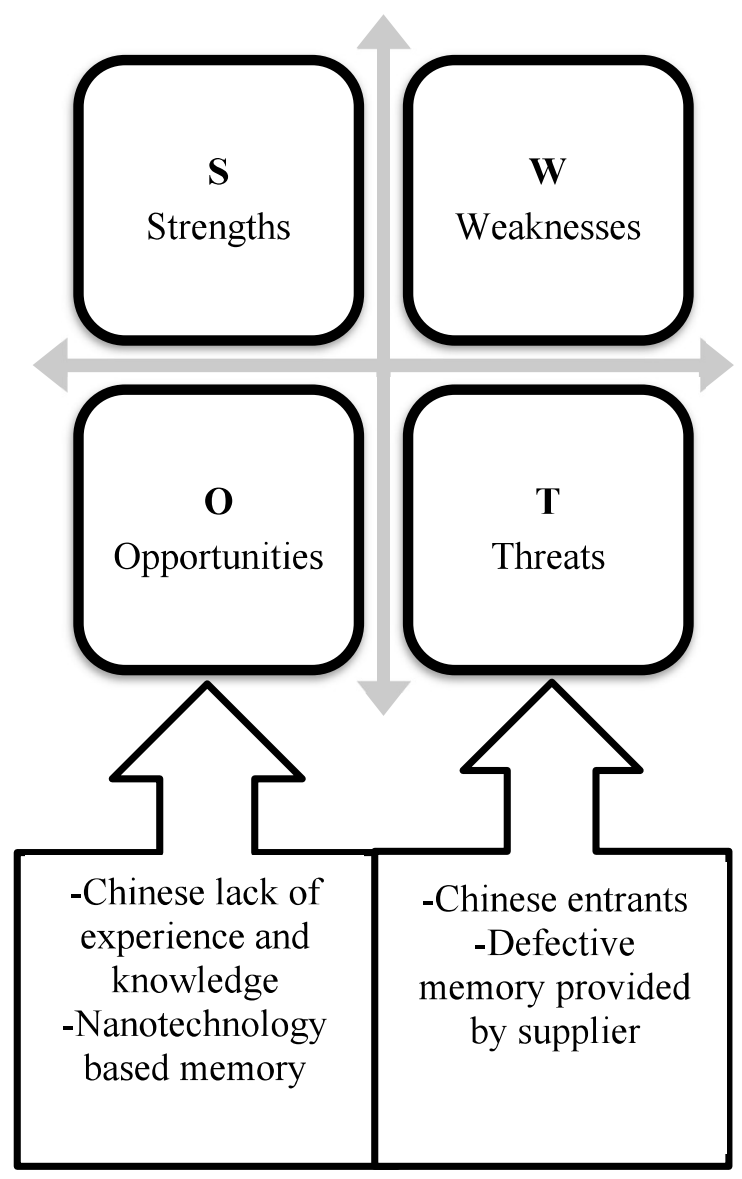

Memory industry has grown by $16 \%$ per year since 1960 . Memory chips such as DRAMs, SRAMs, Flash Memories, Logic Chips are mostly preferred memory chips by customers in global (Kang, 2010). The total sales of memory chips continuously increase in billion in sales in Semiconductor Industry in between 2006 and 2021. In the year 2020, the total sales have reached \$106.44 billion in global market (Daft, 2020).

There is a high competitiveness in the environment of Samsung Electronics Company. Elpida Memory, Inc, Hynix Semiconductor, Inc, Infineon Technologies AG and Micron Technology are the major American competitors of Samsung Electronics Company in U.S. market (Bown, 2020). Other rival companies of Samsung Electronics Co. based on global scale are AMSC, Grace Semiconductor, HeJian Technology and NEC Electronics. The main competitor of Samsung Electronics Company is a Chinese firm called Semiconductor Manufacturing International Corp. (SMIC). SMIC was established in 2000 in Shanghai (Kang, 2010). The Chinese company is the leader on DRAM production in China. The Chinese company has also some alliances with the companies such as Infineon, Elpida and Motorola (Grimes and Du, 2020). 
Why Does This Chinese Company Have to Become Major Concern of Samsung Electronics Co.?

According to total sales of China in this sector, Chinese producers has increased by $117 \%$ from 2017 to 2019 (Grimes and Du, 2020). China has 60\% of World's Chip Manufacturing and Semiconductor Producing Capacity in 2020 and the capacity has been expected to rise to $70 \%$ in 2021 . China has a large pool of engineers and technical experts in that area (Bown, 2020). China also has an ability to raise capital and there are almost no cash flow problems in this sector. There is an abundance of resources and huge amount foreign investors in China as well (Grimes and Du, 2020).

However still Chinese competitors of Samsung Electronics Company are not currently making enough profit as much as they aim but they are aggressively attacking the market to sacrifice the profitability goals and increase their market share that bring new market opportunities to them (Grimes and $\mathrm{Du}, 2020$ ). Chinese competitors are still currently supplying inadequate amount of products to meet existing needs. In order to compete with Chinese competitors Samsung Electronics Company should form a Synergistic Strategic Alliance Partnership with Grace Semiconductor (Daft, 2020). For instance, Samsung Electronics Company has already begun to acquire other foreign companies to gain technology and their focus is to merge with these foreign companies to gain more power on the markets after all. These foreign companies have money, resource, and support of government, so Samsung Electronics Company cannot ignore this situation (Daft, 2020)

\section{FIGURE 3}

\section{SEMICONDUCTOR INDUSTRY SALES IN PERCENTAGE BY COMPONENT TYPES IN 2020}

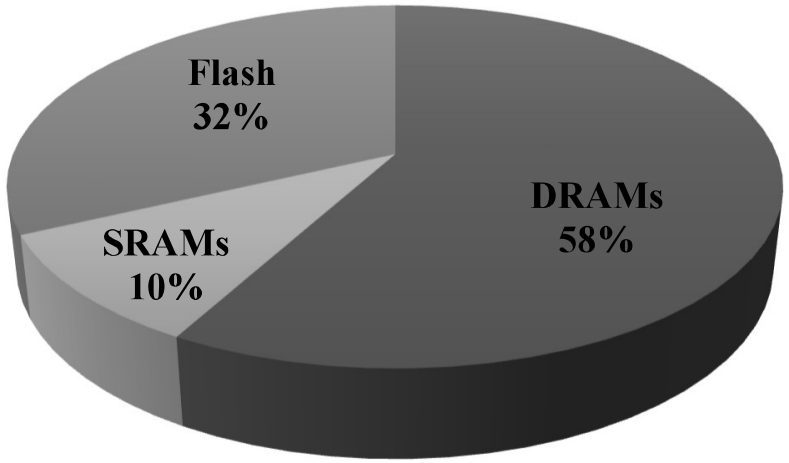

Source: Alsop, (2020)

FIGURE 4

PORTER'S FIVE FORCES FOR SAMSUNG ELECTRONICS COMPANY

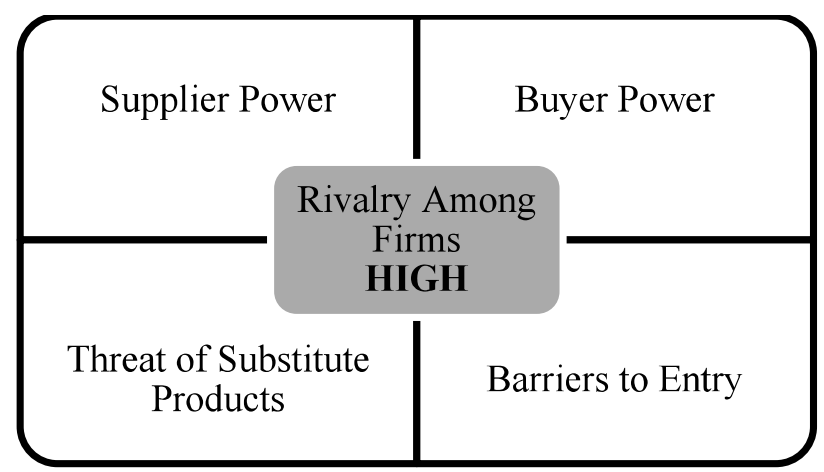

Source: Porter, (2008) 
Samsung Electronics Company has high supplier power and buyer power both. There are several barriers to entry especially in Chinese market but the company has its unique strengths to deal with these barriers (Wang, Sung, Chen and Huang, 2017). There is also high level of threats of substitute products in the company's environment. Similarly, to barriers to entry, Samsung Electronics Company has many core competencies that help company to cope with these threats (Choi, Kim, Kim and Kim, 2013). The rivalry among firms is also high in Samsung Electronics Company's environment.

By applying Porter's Five Forces, Samsung Electronics Company defines clearly its core competencies and forces superior to its competitors. In order to gain competitive advantages among any other competitors in same industry, the company develop realistic and useful long-term strategies (Rasheed and Abbas, 2012). These strategies also enhance Samsun Electronics Company to update revolutionary in its industry.

\section{Internal Analysis of Samsung Electronics Company}

Internal analysis of one company generally comprehends Firm Culture \& Value, Weaknesses, Strengths, Core Competencies and Business Level Strategy.

\section{Firm Culture \& Value of Samsung Electronics Company}

Samsung Electronics Company has invested in its employees and treats them as a family. The company gives a variety of rewards for the accomplishments of its employees. All job functions in Samsung Electronics Company is successful in respect to each project. The division levels in the organization of Samsung Electronics Company are separated from the basis on performance and contribution. Prospective employees were given an aptitude test covering language skills, mathematical knowledge, reasoning and space perception. The company puts place programs to invest employees' global business skills. Samsung invested more in its employees than almost any other competitor in its industry. The decision makers in Samsung Electronics Company break the organizational levels according to the mold of traditional seniority-based promotion. There is also a meritocratic evaluation system which brings equality and fairness among employees (Elia, Petruzzelli and Urbinati, 2020). Younger, high-potential, managers having high ability to speak foreign language are quickly promoted, thus shooting past older employees. Samsung Electronics Company has urged all employees to voice their opinions in organizational environment. The company also has given evaluations and promotions based on A,B,C,D scale (1) every year. Only employees who have earned 2 A's within 3 years eligible for promotion and Samsung Electronics Company gives variable promotions to them.

R\&D engineers and production engineers live together at Samsung's primary campus. They are placed one another's so that engineers could quickly solve design and process engineering problems together. Samsung gives rewards for its employees' accomplishments according to their all job functions or division levels which is based on performance and contribution. The company breaks the mold of traditional seniority-based promotion. There is a Meritocratic evaluation system in the company which allows younger, high-potential, English speaking managers to be quickly promoted (Elia et al., 2020).

\section{Weaknesses of Samsung Electronics Company}

One of the major weaknesses of Samsung Electronics Company is that building semiconductor facilities is difficult and time consuming (Leachman, Kang and Lin, 2002). This is because the production-related machinery is highly sensitive to dust and electronic shock. Besides, Samsung Electronics Company does not have a ready access to Chinese markets. The sectors where Samsung Electronics Company facilitates its corporate activities have high risk. While considering from the point of strengths side high level of risk enhances Samsung Electronics Company to high level of gain but the opposite could be possible though (Wang et al., 2017).

Samsung Electronics Company has also inexperienced young managers and these young managers' lack of experience may cause defaults and problems in organizational processes somehow. Samsung does not have ready access to Chinese market and applies the policy of high Risk- High Gain with its inexperienced young managers. If Samsung Electronics Company tries to get into the niche markets it needs to be able to attract the brightest engineers who will develop the most innovative products. Samsung 
Electronics Company provides lower average rate of salaries than any other rival companies at usual. For instance, Samsung Electronics Company provides 40\% less base salary than Infineon Company and Infenion Company provides $23 \%$ less base salary than Micron Company to its employees in 2020. Having a lower salary can make Samsung Electronics Company less attractive to potential upcoming employees. Since if Samsung Electronics Company aims to get into the niche markets the company requires to be able to attract the brightest engineers who will develop the most innovative products. Having a lower salary can make Samsung Electronics Company less attractive to future qualified work force.

\section{Strengths of Samsung Electronics Company}

Samsung Electronics Company's strengths are that it has high brand value. The meritocratic system that mentioned earlier brings about new employees to shoot past older employees in Samsung Electronics Company (Elia et al., 2020). There is also a system that allows urging all employees to voice their opinions and there is at least a moderate level corporate culture in Samsung Electronics Company.

Samsung Electronics Company makes high employee investment and give much importance to Human Resources Department. Samsung Electronics Company regulates regional specialist programs. There are global strategy groups in Samsung Electronics Company that empower foreign talent recruiting. The company puts place programs to invest employees' global business skills. Samsung invested more in its employees than almost any other competitor in its industry. Prospective employees in the company were given an aptitude test covering language skills, mathematical knowledge, reasoning and space perception and they are given evaluations on an A, B, C, D scale every year, and only those who earned 2 A's within 3 years eligible for promotion.

In terms of Human Resources, the company applies Regional Specialist Program. Additionally, Samsung works with Global Strategy Groups and working internationally provides opportunity of Foreign Talent Recruiting for the company. Also, it has history of successful decision-making by using Stacking Method vs. Trenching Method (Shin, 2017). Stacking is involved tearing down what had been a one-level construction on the chip and replacing it with an apartment building-like structure of cells. Each floor of cells would be conveniently stacked on another. The advantage of stacking is that it is simple and modular which make it far easier to see and fix mistakes. Trenching is involved in digging below the surface of the chip and forming floors below (Shin, 2017). The disadvantage of trenching is that one couldn't look inside to see what is wrong because everything was covered and hidden from view.

There are unique leadership skills in the organization and Samsung Electronics Company's leaders are real industry leaders whom can conjecture reasonably and logically to the future of the company. Samsung Electronics Company also has $10.4 \%$ of Korea's export volume capacity (Park, Choung and Min, 2008).

The history of Samsung Electronics Company comprehends many accomplishments as a result of successful decision-making processes. The company could use the first mover advantages in markets in many times and this led the company to successful achievements with the invention of 8-inch Wafers (Park, Choi, Lee, Koh, Kim, Lee and Park, 2019).

There is a knowledge sharing organizational culture in Samsung Electronics Company. The company also world's leading memory producer for all types of PCs, digital cameras, game players, electronic products and Samsung Electronics Company has the superiority in product design, process efficiency, and quality of manufacturing. Three of products PC's, mobile phones and Flash memories lead Samsung Electronics Company to develop itself more on its core competencies (Park et al., 2019). There are any other different products but Samsung Electronics Company firstly focus on these three. Samsung

Electronics Company uses its core competencies: Quality orientation and the leverage. Samsung Electronics Company grants its strengths to cope with many threats and the high level of uncertainty in its environment (Wang et al., 2017).

\section{Core Competencies of Samsung Electronics Company}

Samsung Electronics Company has produced its products by offering customization around its unique core design. Samsung Electronics Company's products also have superior quality and the customers can easily rely on the utilization and quality of every pieces or components of products. There is a high 
integration of Research and Developments facilities to corporate production activities and processes in Samsung Electronics Company. High integration of advanced technology in production lines can lead Samsung Electronics Company to quicker product resolutions.

Samsung Electronics Company gives importance learning new design rules and applying them in all production processes and customizing products to core design and customer demands. The company has superiority in product design, process efficiency, and quality of manufacturing. The company takes advantaged of Industry 4.0. techniques in its assembly lines and takes cognizance of Research and Development facilities' integration in fab lines (Park et al., 2019).

Samsung is now one of the World's leading memory producers for all types of PCs, digital cameras, game players, electronic products. Regarding memory chip market, DRAM has the highest production volumes among any others. Samsung Electronics Company produces main memories and utilizes in other facets of electronics. Samsung Electronics Company produces also flash Memories and flash memories have reached $32 \%$ of sales volume on Memory Chip Market (Shin, 2017). The memory chip market is regarded as a rapid growth market. Samsung Electronics Company is known as reliable, customizable, trustworthy in this market as well.

Samsung Electronics Company has produced new types of cutting-edge memory chips and has advanced technology integrated production stages as a core competency. In its semiconductor production process, Samsung Electronics Company shapes to desired diameter, invents identical chips. This semiconductor process has thermal, metallurgical and chemical processing steps and allows Samsung Electronics Company to test the products for reliability. Samsung Electronics Company also watches chipused in wrist watches. In its DRAMs business Samsung Electronics Company produces 64K DRAM chips and this production causes unusual internal competition across global Research and Development processes. Samsung Electronics Company has hired two teams for designing 256K DRAMs lately. This strategic decision makes Samsung Electronics Company cooperative and the company could reach their own resolutions more comfortably by this hire. The production of 4Mbit DRAMs allow Samsung Electronics Company to stack and trench respectively (Grimes and Du, 2020).

Stacking is involved tearing down what had been a one-level construction on the chip and replacing it with an apartment building-like structure of cells. Each floor of cells would be conveniently stacked on another. The advantage of stacking: the process of stacking is simple and modular, making it far easier to see and fix mistakes. Trenching is involved in digging below the surface of the chip and creating floors below. The disadvantage of trenching: one couldn't look inside to see what is wrong because everything was covered and hidden from view (Shin, 2017).

Samsung Electronics Company is in a variety of businesses and offers 1200 different variations of DRAM products and flash memories. The products of Samsung Electronics Company have high speed interface I/O. The company serves in telecommunication business by manufacturing mobile phones and network equipment (Kingson and Wen-Hsiang, 2021). Samsung Electronics Company is also in the LCD production sector by making LCD panels for notebook computers, desktop monitors and HDTV. Samsung Electronics Company manufactures digital appliances by producing and selling refrigerators, air conditioners, and washing machines. Furthermore, Samsung Electronics Company is in digital media sector by producing TV, AV equipment, and computers.

\section{Business Level Strategy of Samsung Electronics Company}

Samsung Electronics Company has integrated cost leadership and differentiation business level strategy (Yasuda, 2005). In terms of cost leadership strategy, Samsung Electronics Company has integrated cost leadership and differentiation among its product ranges (Lewis, 2002). Samsung Electronics Company has centered its business facilities on Research and Development. Samsung Electronics Company has optimized its fab lines and has cut fab construction cost by $12 \%$ in 2020 (Grimes and Du, 2020). According to differentiation strategy, Samsung Electronics Company has common core design for different product lines. The company has product mix over 1,200 variations of DRAM products and these all products are customizable products 
Based on Samsung Electronics Company's financial analysis results, the company has a dual advantage that its products have highest prices and lowest costs among any other competitors' products Samsung Electronics Company's Chinese competitors are willing to sacrifice profit for market share but the competitive strategies of Samsung Electronics Company do not allow Chinese competitors to improve their market shares (Cardoso, 2017).

\section{DISCUSSION}

In this study, it could be argued that Samsung Electronics Company provides SMIC with the knowhow and blueprint designs, and SMIC provides Samsung Electronics Company with low-cost production, engineers, and cultural knowledge of Chinese Markets (Grimes and Du, 2020). Samsung Electronics Company should form a synergistic strategic alliance with SMIC. Because this alliance may cause useful upcoming and critical advantages to Samsung Electronics Company (Yasuda and Iijima, 2005).

If these two companies can agree on a strategic alliance, both Samsung Electronics Company and SMIC could have the biggest market share of DRAMs (Grimes and Du, 2020). SMIC is the largest semiconductor producer in China and has unsurpassed experiences in production of semiconductors among any other manufacturers (Yasuda and Iijima, 2005). The only disadvantage could be that this possible strategic alliance may harm the current relationships of Samsung Electronics Company with Infineon, Elpida, and Motorola. This strategic alliance also could not eliminate the betrayal threats of SMIC. Samsung Electronics Company still has to secure itself with its strict privacy policy (Lee and Slater, 2007).

If the Samsung Electronics Company, just decides not to invest in China and avoid strategic alliances with Chinese companies. Samsung Electronics Company should invest heavily on Research and Development facilities more than ever. This strategic decision may bring again some advantages and disadvantages (Lee and Slater, 2007). By deciding not cooperating with any other companies Samsung Electronics Company could secure its own know-how and core competencies easily. However, this decision makes Samsung Electronics Company second largest company in the Chinese market due to many tariffs and high market entrance costs (Grimes and Du, 2020). Chinese government could force Samsung Electronics Company to pay more taxes and such costs because Samsung Electronics Company is foreign investor not a national company. This gives rise to high production costs to Samsung Electronics Company and may prevent the company to compete not only in Chinese market but even in global market too in comparison to its rivals.

Forming a synergistic strategic alliance and partnership with Grace Semiconductor could be solutions for the threats of Chinese competitors of Samsung Electronics Company (Yasuda and Iijima, 2005). To convince Samsung Electronics Company to be partner of Grace Semiconductor Company; it is better searching more on Grace's Operating Philosophy and giving details on it (Gnyawali and Park, 2011). Grace Semiconductor Company's vision is to become a leading foundry in China. The mission statement of Grace Semiconductor Company is supplying high quality and advance value-added technology solutions. Grace Semiconductor Company achieve its goal by maintaining a high level of customer satisfaction with the aid of strategic partners (Gnyawali and Park, 2011). 


\section{FIGURE 5}

\section{THE IMPLEMENTATION OF COMPETITIVE STRATEGY SUGGESTIONS AT SEVEN STEPS TO THE STRATEGIES OF SAMSUNG ELECTRONICS COMPANY}

\begin{tabular}{|c|c|}
\hline Step 1 & - Contact Grace Semiconductor \\
\hline Step 2 & -Arrange a Meeting with Top Management \\
\hline Step 3 & -Agree Upon Terms for an Alliance \\
\hline Step 4 & - Assess the Current Grace Factory and Equipment in Beijing \\
\hline Step 5 & $\begin{array}{l}\text { - Provide Grace with new Equipment and the Personnel } \\
\text { Training Required for DRAM Production }\end{array}$ \\
\hline Step 6 & -Provide Low-End DRAM Design Blueprints \\
\hline Step 7 & - Begin Mass Production of Low-End DRAM in China \\
\hline
\end{tabular}

Developing a partnership with Grace Semiconductor could be a solution due to the fact that both Samsung Electronics Company and Grace Semiconductor could share their own core values with each other to gain more power in existing markets (Lee and Slater, 2007). After this partnership, they could more focus on customer orientated production strategies. This partnership could maintain continuous learning and sustainable innovation for two companies (Gnyawali and Park, 2011). Additionally, this partnership could sustain streamline, efficiency, organizational harmony, teamwork, seamless cooperation for both Samsung Electronics Company and Grace Semiconductor Company (Lee and Slater, 2007). The partnership also brings trust and encouragement to employees and could improve their motivation (Yasuda, 2005).

Samsung Electronics Company and Grace Semiconductor Company can lower their production costs and avoid tariffs by this partnership (Lewis, 2002). They reach cultural penetration and pool of qualified engineers. The partnership also can lessen threats of betrayal and Samsung Electronics Company and Grace Semiconductor Company could easily focus on low-end markets to broaden their market share in new markets. On the other hand, there is a possibility that this partnership may cause Grace Company to grow more rapidly than Samsung Electronics Company and Samsung Electronics Company may support its future possible enemy unknowingly (Rolf, 2020). Samsung Electronics Company easily shoots the past older employees, this can create stress and decrease their performance. Thus, Samsung Electronics Company should give more importance to its older employees too.

\section{CONCLUSION}

Samsung Electronics Company with its strong internal dimensions and highly structured business process and facilities is a leader in Semiconductor Industry. The company's high quality and technology advanced products (PC's, mobile phones, flash memories, semiconductor components and so on) Samsung Electronics Company could cope with the threats in its environment. The realistic external analysis which comprehends Porter's Five Forces Analysis in order to analyze competitive environment and internal analysis that includes firm culture, firm value, strengths and weaknesses and lastly core competencies allow Samsung Electronics Company to plan effective strategies and to manage realistic decision making process 
at every level of organizational structure (Leachman et al., 2002). The company's qualified and high-tech products help Samsung Electronics Company to gain superior advantage among any other rival companies.

After giving information about Samsung Electronics Company's history and overview, this study focuses on two main analyses: external and internal analyses while discussing situational factors which influencing Samsung Electronics Company to set a practical and efficient strategic business plan. This study also gives some suggestions to Samsung Electronics Company in order to the company maintain sustainable success in the future.

The main objective of this study make deep research on Semiconductor and other technology integrated industries while deeply analyzing the external and internal dimensions of sector leaders both in global and in leader countries in specialized these industries such as U.S.A. and China. The study has reached inner insights and useful conclusions for the future researches and practical implementations and suggestions especially for Samsung Electronics Company and any other companies which aim to be accomplished in these industries.

In conclusion, this study recommends Samsung Electronics Company that the company should acquire a Chinese firm while investing in new niche markets. This recommendation may allow Samsung Electronics Company to have a stronger position in the continuously fast changing Semiconductor Industry. Samsung Electronics Company also has the capital resources to undertake both initiatives simultaneously, which the company should take advantage of since most of its competitors lack the ability to do so. Besides this strategic move allows Samsung Electronics Company to keep up with the fast pace of the industry by investing in their innovative capabilities, while overcoming the new threats it is facing at the same time.

\section{ENDNOTE}

1. A, B, C, D scale is similar to Likert scale and measures the performance of employees in Samsung Electronics Company based on four main bases.

\section{REFERENCES}

Alsop, T. (2020). Semiconductor memory components global revenue 2006-2021. Statista. Retrieved from: www.statista.com

Bown, C.P. (2020). How the United States marched the semiconductor industry into its trade war with China. East Asian Economic Review, 24(4), 349-388.

Bown, C.P. (2020). How the United States marched the semiconductor industry into its trade war with China (pp. 20-16).

Brown, C., \& Linden, G. (2011). Chips and change: How crisis reshapes the semiconductor industry. MIT Press, 1(3), 165-199. California. ISBN: 978-0-262-01346-8

Brown, C., \& Linden, G. (2011a). Chips and Change: How Crisis Reshapes the Semiconductor Industry (Vol. 1(3), pp. 165-199). The MIT Press. ISBN: 978-0-262-01346-8

Cardoso, E.A.R.P. (2017). Examining the differences of the internationalization strategies of two of the major brands in the smartphone industry-Apple inc. versus Samsung electronics (Doctoral dissertation). Retrieved from http://hdl.handle.net/10071/13973

Choi, K.M., Kim, T.H., Kim, K.S., \& Kim, S.G. (2013). Case Study: Hazard Identification of Powder Generated from a Chemical Vapor Deposition Process in the Semiconductor Manufacturing Industry. Journal of Occupational and Environmental Hygiene, 10(1), D1-D5.

Daft, R.L. (2020). Organization theory \& design. Cengage learning, 13(1) 145-693. ISBN: 978-35744514-3

Elia, G., Petruzzelli, A.M., \& Urbinati, A. (2020). Implementing open innovation through virtual brand communities: A case study analysis in the semiconductor industry. Technological Forecasting and Social Change, 155, 119994.

Gnyawali, D.R., \& Park, B.J.R. (2011). Co-opetition between giants: Collaboration with competitors for technological innovation. Research Policy, 40(5), 650-663. 
Grimes, S., \& Du, D. (2020). China's emerging role in the global semiconductor value chain. Telecommunications Policy, 101959.

Kang, J. (2010). A Study of the DRAM Industry (Doctoral dissertation, Massachusetts Institute of Technology), pp. 6-52.

Kingson, A., \& Wen-Hsiang, L.A.I. (2021). AHP analysis of classifying and positioning the crucial influential factors of brand establishment in the semiconductor industry. Journal of Economics and Political Economy, 7(4), 234-260.

Leachman, R.C., Kang, J., \& Lin, V. (2002). SLIM: Short cycle time and low inventory in manufacturing at Samsung Electronics. Interfaces, 32(1), 61-77.

Lee, J., \& Slater, J. (2007). Dynamic capabilities, entrepreneurial rent-seeking and the investment development path: The case of Samsung. Journal of International Management, 13(3), 241-257.

Lee, K.H., \& Kim, J.W. (2011). Integrating suppliers into green product innovation development: An empirical case study in the semiconductor industry. Business Strategy and the Environment, 20(8), 527-538.

Lewis, J.D. (2002). Partnerships for profit: Structuring and managing strategic alliances. Simon and Schuster.

Liao, C.C., \& Chen, C.C. (2020, September). Using Collaborative Physics Technologies to Integrate Enterprise Cloud Services. In 2020 IEEE International Conference on Consumer ElectronicsTaiwan (ICCE-Taiwan) (pp. 1-2). IEEE

Park, D.U., Choi, S., Lee, S., Koh, D.H., Kim, H.R., Lee, K.H., \& Park, J. (2019). Occupational Characteristics of Semiconductor Workers with Cancer and Rare Diseases Registered with a Workers' Compensation Program in Korea. Safety and Health at Work, 10(3), 347-354.

Park, T.Y., Choung, J.Y., \& Min, H.G. (2008). The cross-industry spillover of technological capability: Korea's DRAM and TFT-LCD industries. World Development, 36(12), 2855-2873.

Porter, M.E. (2008). The five competitive forces that shape strategy. Harvard Business Review, 86(1), 78.

Rasheed, R., \& Abbas, R.N.Y. (2012). Samsung Electronics and Apple, Inc.: A Study in Contrast in Competitive Analysis in 21st Century, 4(12), 21-28. ISSN 2224-6096

Rolf, S. (2020). China's Uneven and Combined Development. Studies in the Political Economy of Public Policy, I(1), 59-86. Palgrave Macmillan. ISBN: 978-3-030-55558-0

Samsung Community. (2020). https://eu.community.samsung.com/

Shin, J.S. (2017). Dynamic catch-up strategy, capability expansion and changing windows of opportunity in the memory industry. Research Policy, 46(2), 404-416.

Sodhi, M.S., \& Lee, S. (2007). An analysis of sources of risk in the consumer electronics industry. Journal of the Operational Research Society, 58(11), 1430-1439.

Wang, C.C., Sung, H.Y., Chen, D.Z., \& Huang, M.H. (2017). Strong ties and weak ties of the knowledge spillover network in the semiconductor industry. Technological Forecasting and Social Change, 118, 114-127.

Yasuda, H. (2005). Formation of strategic alliances in high-technology industries: Comparative study of the resource-based theory and the transaction-cost theory. Technovation, 25(7), 763-770.

Yasuda, H., \& Iijima, J. (2005). Linkage between strategic alliances and firm's business strategy: The case of semiconductor industry. Technovation, 25(5), 513-521. 